\title{
ELEMEN VISUAL PADA DESAIN MEDIA PROMOSI MUSEUM WAYANG JAKARTA
}

\author{
Yayah Rh' ${ }^{1)}$, Dendi Pratama ${ }^{2)}$, Puji Anto ${ }^{3)}$ \\ Program Studi Desain Komunikasi Visual, \\ Fakultas Bahasa Dan Seni, Universitas Indraprasta PGRI \\ Jl. Nangka No. 58 C, Tanjung Barat, Jakarta Selatan, 12530, Indonesia \\ Silvi.aini97@gmail.com
}

\begin{abstract}
Abstrak
Saat ini masih banyak yang belum memahami pentingnya penggunaan elemen visual secara konsisten dalam sebuah media promosi. Tidak adanya konsistensi antar media promosi, akan menciptakan kesenjangan di dalam suatu brand sehingga media promosi terkesan tidak saling mendukung. Museum Wayang Jakarta adalah Museum Wayang terlengkap di Indonesia yang memiliki daya tarik tersendiri bagi wisatawan domestik maupun mancanegara. Museum Wayang Jakarta menggunakan media promosi untuk memperkenalkan dan menarik wisatawan mengunjunginya. Media promosi yang digunakan adalah brosur, booklet, dan post card. Media promosi yang digunakan Museum Wayang Jakarta ini layak untuk dikaji. Penelitian ini bertujuan untuk mengetahui konsistensi desain visual pada media promosi yang digunakan sebagai branding Museum Wayang dilihat dari elemen desain yang digunakan. Hasil analisis elemen desain menunjukkan penggunaan warna yang kurang sesuai atau mewakili Museum Wayang seperti; putih, biru. Ketiga media promosi menggunakan jenis font sans serif, yaitu Calibri (Body). Tata letak yang digunakan pada media brosur dan post card ialah jenis axial, sedangkan pada media booklet menggunakan layout jenis jumble. Ditambahkan pula analisis prinsip desain sebagai hal yang tidak terpisahkan dari elemen desain, seperti kesatuan, penekanan (emphasis), keseimbangan (balance).
\end{abstract}

Kata Kunci: Media Promosi, Museum Wayang, Elemen Visual.

\begin{abstract}
Currently, many still do not understand the importance of using visual elements consistently in a promotional medium. The absence of consistency between promotional media will create gaps in a brand so that the promotional media do not seem to support each other. The Jakarta Wayang Museum is the most comprehensive puppet museum in Indonesia which has a special attraction for domestic and foreign tourists. The Jakarta Wayang Museum uses promotional media to introduce and attract tourists to visit it. The promotional media used are brochures, booklets, and post cards. The promotional media used by the Jakarta Wayang Museum is worthy of study. This study aims to determine the consistency of visual design in the promotional media used as wayang museum branding in terms of the design elements used. The results of the design element analysis indicate the use of colors that are not suitable or representative of wayang museums such as White blue. The three promotional media use the sans serif font, Calibri (Body). The layout used in brochure and post card media is axial type, while booklet media uses the jumble type layout. Also added is the analysis of design principles as inseparable from design elements, such as unity, emphasis (emphasis), balance (balance).
\end{abstract}

Keywords: Media Promotion, Puppet Museum, Visual Elements.

Correspondence author: Yayah Rh, Silvi.aini97@gmail.com, Jakarta, and Indonesia 


\section{PENDAHULUAN}

Museum adalah tempat pembelajaran dan nilai-nilai kehidupan pada masa lalu ke masa kini dan masa yang akan datang, Museum juga bukan hanya menjadi "gudang budaya", tetapi merupakan pusat pengetahuan budaya atau pemancar ilmu pengetahuan yang diperoleh dari koleksi dan menjadikannya informasi bagi masyarakat (Agus dalam Aditya, 2015: 4).

Indonesia saat ini memiliki banyak museum, salah satunya Museum Wayang yang berada di Kota Tua Jakarta tepatnya terletak di Jalan Pintu Besar Utara No. 27 Jakarta Barat yang diresmikan oleh Gubernur DKI Jakarta, Letnan Jenderal Marinir H. Ali Sadikin Pada tanggal 13 Agustus 1975. Museum Wayang ini sebelum diresmikan adalah sebuah gereja dan mengalami perbaikan tiga kali. Museum Wayang sendiri saat ini memiliki memiliki 6377 koleksi yang terdiri dari beberapa jenis dan bahan wayang yang ada di Indonesia dan beberapa koleksi dari luar negeri, seperti Cina, India, Kamboja, Amerika.

UNESCO menetapkan wayang sebagai warisan kesenian dunia dari Indonesia pada tanggal 7 November 2003. Hal itu membuat nilai tambah untuk Museum Wayang dan akan berdampak pada jumlah pengunjung baik dari dalam, maupun luar negeri. Prestasi tersebut akan sangat berarti jika disampaikan dengan baik pada masyarakat.

Media promosi berperan penting untuk memperkenalkan dan mengajak masyarakat luas mengunjungi Museum Wayang Jakarta. Promosi adalah semua kegiatan untuk membantu penjualan suatu produk atau jasa di setiap tempat jaringan penjualan, mulai dari bahan presentasi yang digunakan oleh tenaga penjual ketika melakukan penawaran hingga siaran niaga di media massa (televisi dan surat kabar) untuk mengikat pelanggan melalui kesan yang menyenangkan terhadap yang diiklankan (Matondang dan Fahmi, 2000: 3).

Pembuatan media promosi tidak dapat terpisahkan dari keilmuan desain komunikasi visual. Gert Dumbar seorang desainer Belanda mengatakan desain grafis sebagai cikal bakal desain komunikasi visual tidak hanya menangani desain untuk percetakan saja, tetapi juga moving image, display, dan pameran. Secara singkat desain komunikasi visual dapat diartikan sebagai cara atau rancangan berkomunikasi kepada pihak lain melalui visualisasi atau media visual (Anindita dan Riyanti, 2016: 1-14).

Seorang desainer menggunakan elemen visual untuk menunjang sebuah desain, Elemen-elemen desain yang seling digunakan antara lain adalah tipografi, ilustrasi, simbolisme, warna. Elemen-elemen ini bisa digunakan sendiri-sendiri, bisa juga digabungkan. Oleh karena itu, dalam membuat rancangan tidak hanya sekadar mengumpulkan atau menyatukan beberapa elemen visual, tetapi kumpulan elemen tadi harus saling mendukung atau satu-kesatuan untuk menyampaikan informasi secara singkat, tetapi mampu mewakili skala besar.

Kajian berkaitan dengan pentingnya elemen desain dalam sebuah perancangan telah dilakukan oleh Swasty dan Utama (2017: 1-16) dengan judul Warna sebagai Identitas Merek pada Website yang menyimpulkan bahwa cara efektif untuk memunculkan identitas merek adalah dengan memanfaatkan unsur visual yang merangsang penglihatan. Warna sebagai identitas merek harus konsisten diterapkan pada produk dan program pemasaran (kemasan, interior toko, signage, dan media promosi lainnya termasuk website). Penelitian tentang tipografi juga sudah pernah dilakukan oleh Sabetti (2011: 149-150) bahwa pemilihan tipografi bertujuan untuk membuat karya desain itu lebih menarik dan komunikatif ketika digunakan dalam media promosi. Menurut Sutedjo Hadiwasito (1996), dalam penelitiannya terkait ilustrasi yang berjudul Penggunaan Ilustrasi sebagai Daya Tarik pada Iklan Media Cetak menyimpulkan bahwa Pemilihan ilustrasi sebagai daya tarik dalam iklan media cetak harus dipertimbangkan masak-masak dari mulai pemilihan jenis ilustrasi sampai visualisasi. Peletakan ilustrasi dalam komposisi iklan juga harus menarik, mata mempunyai alur pandang yang liar (dalam Hartanto 2001: 40-48).

Berdasarkan pemaparan di atas bahwa elemen-elemen desain mempunyai peran penting dalam menyampaikan pesan pada media promosi. Keterwakilan objek yang dituangkan dalam konsep desain harus menjadi prioritas. Oleh sebab itu, pada penelitian ini akan mengupas elemen-elemen desain yang ada dalam media promosi untuk mengukur keterwakilan dari keseluruhan Museum Wayang Jakarta. 


\section{METODE PENELITIAN}

Jenis penelitian yang digunakan adalah deskriptif dengan pendekatan kualitatif. Metode penelitian deskriptif sendiri adalah suatu penelitian yang dilakukan untuk melukiskan variabel demi variabel. Satu demi satu yang bertujuan untuk mengumpulkan informasi aktual secara rinci yang melukiskan gejala yang ada (Rakhman dalam Novianti, 2017:25).

Penelitian deskriptif adalah penelitian yang bertujuan untuk menjelaskan apa-apa saja yang saat ini berlaku. Di dalamnya terdapat upaya mendeskripsikan, mencatat, analisis, dan menginterprestasikan kondisi-kondisi yang sekarang ini terjadi atau ada. Penelitian kualitatif akan membantu dalam mengkaji desain, khususnya elemen visual dari media promosi Museum Wayang.

Data penelitian yang didapat berasal dari hasil studi beberapa literatur yang diolah dan juga dengan melakukan observasi ke Museum Wayang Jakarta. Berdasarkan teori yang disebutkan, alasan pemilihan metode penelitian kualitatif adalah untuk mendeskripsikan dan mengungkap elemen desain pada media promosi Museum Wayang, seperti warna, ilustrasi, tipografi, tata letak.

\section{HASIL DAN PEMBAHASAN}

\section{Museum Wayang Jakarta}

Museum Wayang Jakarta Terletak di Jalan Pintu Besar Utara No. 27 Jakarta Barat/ Kota. Pada tahun 1640 terdapat sebuah gereja tua yang bernama "de oude Holandsche Kerk" yang merupakan tempat peribadatan bagi penduduk sipil dan tentara Belanda yang tinggal di Batavia. Gereja tersebut hanya berfungsi sampai tahun 1732. Pada tahun 1733 gereja tersebut diperbaiki dan diubah namanya menjadi "de oude Holandsche Kerk" dan terus berdiri sampai tahun 1808. Akibat terjadi gempa bumi, gedung gereja baru tersebut mengalami kerusakan, kemudian lokasi tempat gereja yang rusak tersebut dibangun gedung yang ada saat ini dipakai sebagai museum. Pada tanggal 13 juni 1975 setelah proses penataan koleksi wayang selesai, Gubernur DKI Jakarta H. Ali Sadikin meresmikan pembukaan Museum Wayang Jakarta. Museum Wayang Jakarta merupakan Unit Pelaksana Teknis Dinas Kebudayaan dan Permuseuman di bidang pewayangan, hal ini berdasarkan Surat Keputusan Gubernur Provinsi DKI Jakarta Nomor 134 tahun 2002 tentang Organisasi dan Tata Kerja Dinas Kebudayaan dan Permuseuman Provinsi Daerah Khusus Ibukota Jakarta (BAB VIII, Pasal 33,1).

\section{Koleksi Museum Wayang}

Museum Wayang hingga saat ini mempunyai 6377 buah wayang. Wayang yang ada tidak hanya berasal dari Indonesia saja, ada juga yang berasal dari Cina, Thailand, Kamboja, Suriname, Prancis, India, Pakistan, Vietnam, Inggris, Amerika, dan Malaysia. Museum Wayang juga menyajikan kegiatan-kegiatan yang berhubungan dengan wayang dan juga fasilitas yang memungkinkan untuk diadakannya kegiatan dan pagelaran wayang.

\section{Media Promosi}

\section{Booklet}

Museum Wayang Jakarta memiliki tiga media promosi, yaitu:

Media promosi yang digunakan oleh Museum Wayang salah satunya adalah Booklet. Booklet tersebut memuat beberapa informasi tentang museum yang ada di Kota Tua Jakarta, salah satunya Museum Wayang. Booklet berisi 14 halaman data tentang Museum Wayang Jakarta. 14 halaman ini menginformasikan koleksi Museum Wayang, fasilitas ruang pamer, ruang pagelaran, ruang 3 dimensi, waktu operasional, harga tiket, dan alamat Museum Wayang. 


\section{Brosur}

Brosur Museum Wayang berisi tentang beberapa foto koleksi wayang, ruang pamer Museum Wayang, foto workshop, informasi harga tiket, jam operasional, dan denah lokasi yang bisa diakses melalau scan $Q r$.

\section{Post card}

Post card Museum Wayang memiliki berbagai macam gambar, seperti gambar Wayang Wahyu dan di bawahnya terdapat $Q r$ code yang berfungsi untuk memberikan informasi tentang Wayang Wahyu.

\section{Kajian Teori}

Dalam menganalisis sebuah media diperlukan landasan teori sebagai pisau analisisnya. Teori yang digunakan di antaranya:

a. Warna (Color), efek sebuah warna dalam komposisinya ditentukan oleh situasi karena warna selalu dilihat dalam hubungan dengan lingkungannya akan memiliki kekuatan sendiri, kualitas dan kuantitas keleluasaannya merupakan faktor yang sangat menunjang (Pujiriyanto, 2005:43).

b. Tipografi, seni menyusun huruf-huruf sehingga dapat dibaca, tetapi masih memiliki nilai desain. Tipografi digunakan sebagai metode untuk menerjemahkan kata-kata/lisan ke dalam bentuk tulisan/visual (Cenadi, 1999: 5).

c. Ilustrasi, suatu bidang dari seni yang berspesialisasi dalam penggunaan gambar yang tidak dihasilkan dari kamera atau fotografi (nonfotographic objek) untuk visualisasi (Cenadi, 1999: 5).

d. Tata letak (layout), dijabarkan sebagai tata letak elemen-elemen desain terhadap suatu bidang dalam media tertentu untuk mendukung konsep/pesan yang dibawanya (Rustan, 2017: 1).

Dalam perancangan sebuah desain juga perlu diperhatikan prinsip desainnya, maka teori yang digunakan sesuai pendapat Vinsensius (2004), bahwa desain yang paling baik adalah seperti apa yang terkandung dalam prinsip berikut:

a. Kesederhanaan, berguna untuk memudahkan pembaca memahami isi pesan yang disampaikan. Dalam penggunaan huruf, mulai dari huruf judul (headline), subjudul (body text) sebaiknya jangan menggunakan jenis font yang ornamental dan rumit. Prinsip ini bisa diterapkan penggunaan elemen ruang kosong (white space) dan tidak menggunakan terlalu banyak unsur-unsur aksesoris.

b. Keseimbangan, keadaan atau kesamaan antara kekuatan yang saling berhadapan dan menimbulkan adanya kesan seimbang secara visual.

c. Kesatuan, kohesi, konsistensi, ketunggalan atau keutuhan, yang merupakan isi pokok dari komposisi.

d. Penekanan (aksentuasi), untuk menarik perhatian pembaca sehingga ia mau melihat dan membaca bagian desain yang dimaksud.

e. Irama, pengulangan unsur-unsur pendukung karya seni. Irama merupakan selisih antara dua wujud yang terletak pada ruang, desain mementingkan interval ruang atau kekosongan atau jarak antar objek. 


\section{Analisis Elemen Visual Media Promosi Museum Wayang}

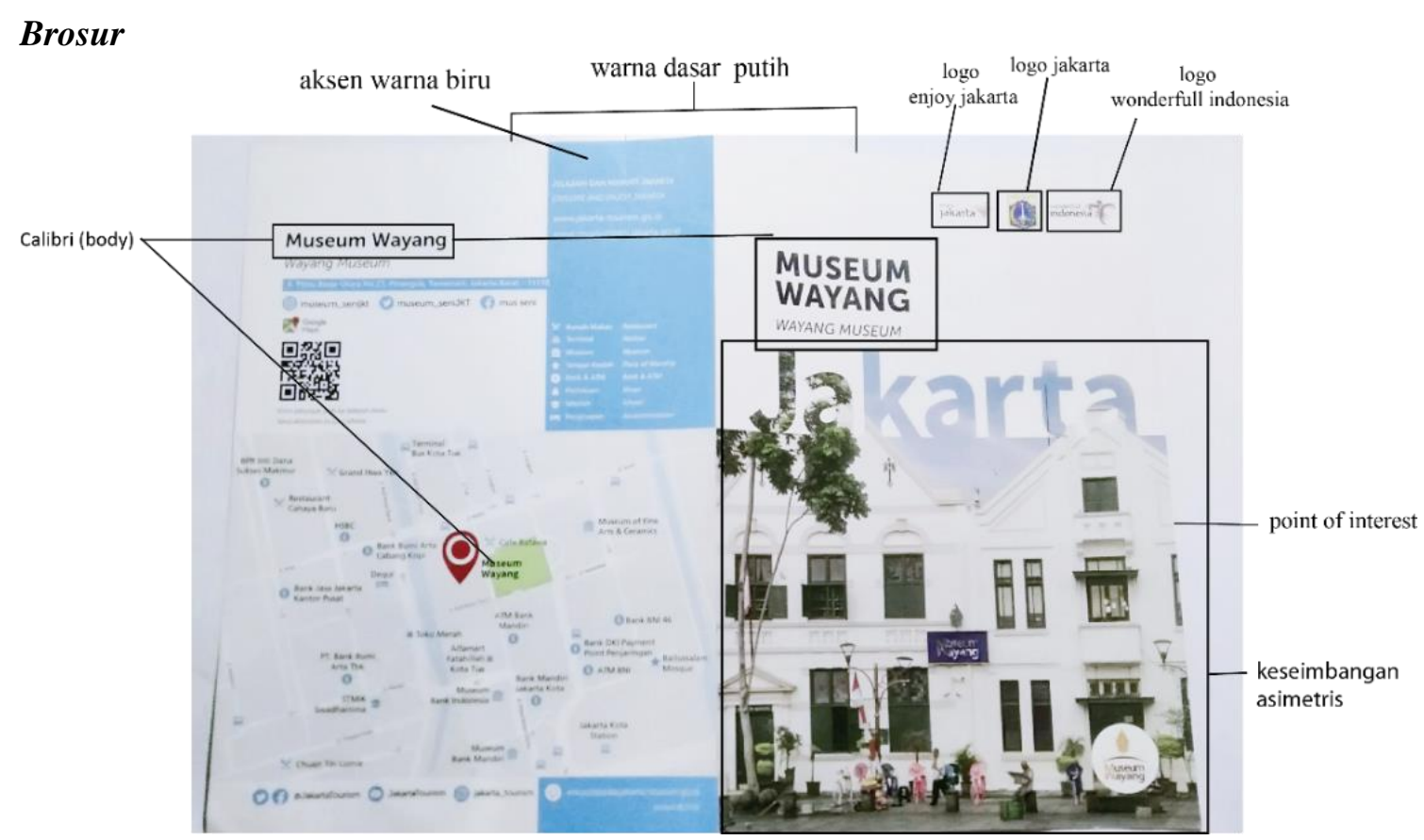

Gambar 1 Brosur bagian depan dan belakang Sumber: Dokumen pribadi

Brosur adalah aplikasi desain yang dicetak (print). Brosur biasanya di lipat, atau dijahit dan kadang berukuran kecil hingga bisa dimasukan saku. Ukuran brosur bermacam-macam, dan harus didesain sesuai besar kecilnya anggaran. Brosur biasanya digunakan sebagai perangkat pemasaran sebuah perusahaan. Jadi, selain menampilkan profil produk atau jasa yang ditawarkan perusahaan, di dalam brosur juga ditampilkan profil perusahaan. Yang terpenting dalam brosur harus menggambarkan perusahan dan sesuai dengan tujuan perusahaan, baik secara visual maupun isinya (Yulistianti 2008:3).

1) Warna

Pada bagian depan terdapat dua jenis warna yang digunakan yaitu warna putih, hitam, biru, dan merah. Warna putih menurut Zharandont (2015:4) memberikan kesan kebebasan dan keterbukaan. Warna hitam pada tulisan Museum Wayang berfungsi sebagai penguat yang memberikan kesan kuat atau penekanan terhadap objek yang menjadi pusat perhatian. Menurut Zharandont (2015:4), warna hitam akan memberikan kesan elegan. Oleh karena itu, elemen apa pun jika dikombinasikan dengan warna hitam akan terlihat menarik. Sebagian besar warna yang digunakan warna putih. Pada bagian belakang brosur terdapat empat warna, warna putih seperti bagian depan warna putih juga digunakan sebagai warna dasar, Warna biru terdapat pada background alamat Museum Wayang, alamat website, logo media sosial dan fasilitas yang berdekatan dengan gedung Museum Wayang. Warna hitam terdapat pada sebagian tipografi yang digunakan dan $Q r$ petunjuk arah. Warna merah terdapat pada tanda maps yang menjadi point inters pada brosur.

Dari warna yang digunakan pada media promosi di atas kurang sesuai dengan wayang karena tidak mengonotasikan wayang (wawancara dengan Aryan Pramudito selaku Digital Creative Director 1 Juli 2020) "warna biru sendiri tidak mengonotasikan wayang, warna wayang adalah warna tanah, bahkan wayang-wayang yang non-Jawa pun menggunakan warna primer, dan semua wayang tidak mempunyai roots warna pastel".

2) Tipografi 
Tipografi yang ada pada brosur adalah sans serif. San serif memiliki bentuk geometris mendekati bentuk-bentuk dasar/ basic shape (segi empat, segi tiga, lingkaran) (Rustan 2011: 46). Terdapat satu jenis font sans serif yang digunakan pada brosur, yaitu Calibri (body). Terlihat adanya konsistensi pada penggunaan font, hal itu akan menghasilkan konsistensi massage. Dengan menggunakan font jenis san serif menjadikan kesan museum terlihat lebih stylish.

3) Ilustrasi

Ilustrasi berupa foto dihasilkan dengan teknik fotografi menggunakan kamera. Teknik fotografi juga dapat memberikan ekspresi gaya tertentu sehingga objek menjadi realis, eksklusif, dan persuasif. Teknik fotografi juga dapat mengubah suasana lebih anggun dan memesona dengan menghasilkan sebuah gambar dengan pengaturan objek yang tepat serta permainan sinar yang tepat akan menghasilkan sebuah gambar yang bagus (Pujiriyanto, 2005:42). Gambar bangunan Museum Wayang sangat dominan sehingga memberikan informasi atau menyampaikan kepada masyarakat seperti apa bangunan Museum Wayang. Gambar lain seperti logo enjoy Jakarta, logo DKI Jakarta, wonderful Indonesia terdapat pada bagian kanan atas yang menginformasikan kepada masyarakat bahwa Museum Wayang bekerja sama dengan beberapa lembaga tersebut.

4) Tata Letak

Layout pada brosur menggunakan jenis axial karena memiliki tampilan visual yang kuat di tengah yaitu gambar bangunan Museum Wayang dengan tampilan elemen pendukung di sekelilingnya seperti headline, logo Jakarta, logo enjoy Jakarta dan logo wonderful indonesia. axial layout memiliki tampilan visual yang kuat di tengah halaman dengan tampilan elemen pendukung di sekeliling gambar utama biasanya berupa gambar atau tulisan yang berhubungan dengan tampilan dengan tampilan di tengah sebagai titik pusatnya (Kusrianto, 2007:310).

5) Prinsip Desain pada Brosur

Keseimbangan (Balance) yang digunakan pada bagian depan brosur yaitu asimetris di mana susunan unsur-unsurnya pada setiap sisi ditempatkan berbeda, tetapi tetap memberikan kesan seimbang. Hal itu sesuai dengan pendapat Stewart (2011:22), bahwa keseimbangan mengacu pada distribusi berat atau kekuatan di antara unit-unit visual. Kesatuan (Unity), terdapat kesatuan antarelemen satu dengan lainnya, penggunaan warna yang sama pada setiap elemen memengaruhi kesatuan pada desain brosur tersebut. Hal itu didukung oleh pendapat Zulkifli (2018:50) bahwa kesatuan (Unity) adalah bagian dari prinsip komposisi tata rupa yang harus diperhatikan dalam karya seni rupa, kesatuan adalah kualitas hubungan antara bagian-bagian dari elemen yang menyatu.

\section{Booklet}

Booklet termasuk salah satu jenis media promosi. Menurut Efendi dalam Gustaning (2014: 22), booklet merupakan media berbentuk buku kecil yang berisi tulisan atau gambar atau keduanya, sedangkan menurut Efendi Sholeh dalam Ramadhani dan Hariastuti (2018 : 359) menyebutkan bahwa booklet adalah sarana periklanan yang mampu menarik banyak konsumenkonsumen produktif. 

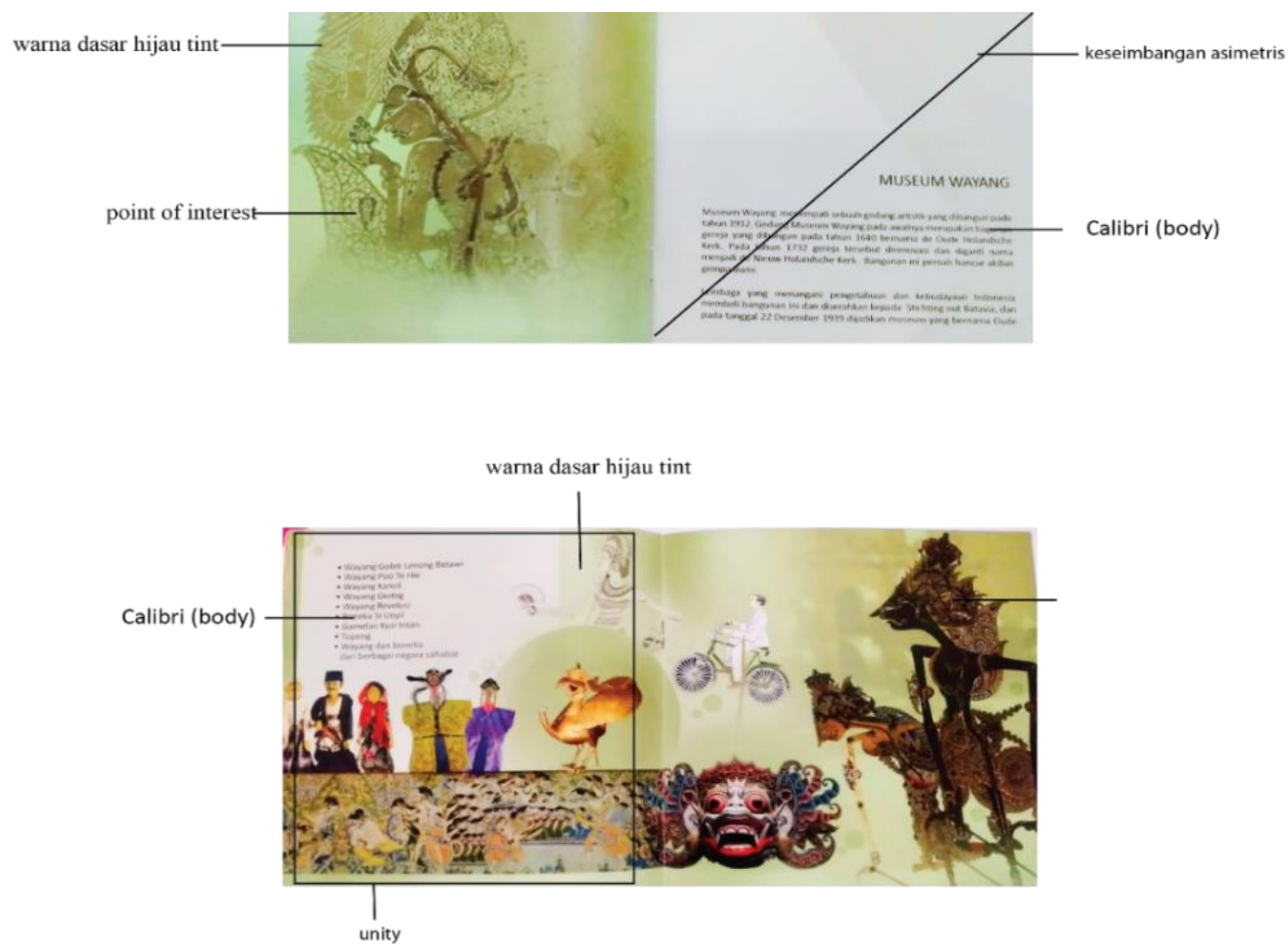

Gambar 2. Booklet

Sumber: Dokumen pribadi

1) Warna

Warna merupakan unsur yang sangat tajam untuk mengetuk kepekaan penglihatan sehingga mampu merangsang munculnya rasa haru, sedih, gembira mood, semangat, dan lain-lain (Kusrianto, 2007: 46). Hijau tint merupakan warna yang menjadi warna dasar booklet. Warna hijau sendiri identik dengan alam dan mampu memberi suasana tenang dan santai. Warna hijau yang digunakan pada media promosi di atas mengonotasikan wayang. Hal itu sesuai dengan pendapat Farid Tirtosudiro bahwasanya warna yang dapat mengonotasikan wayang adalah warna klasik cokelat kayu, emas atau warna turunan elemen alam atau warna cat yang ada di wayang, seperti hijau.

2) Tipografi

Sebuah font yang baik harus jelas, terbaca, dan mudah dipahami. Sebuah font hanya membutuhkan tingkat keterbacaan yang tinggi (Rustan 2011:74). Tipografi dalam booklet terdapat satu jenis font sans serif, yaitu Calibri (body). Penggunaan font jenis san serif secara konsisten digunakan di dua media promosi Museum Wayang, brosur dan booklet. Hal itu ingin menekankan kembali bahwa museum dikesankan lebih stylish. Hal itu juga sesuai dengan pendapat peneliti yang lain, yaitu Aryan Pramudito Bahwasanya bahwa penggunaan font jenis san serif pada sebuah desain dapat memunculkan kesan stylish.

3) Ilustrasi

Ilustrasi adalah gambar atau foto yang bertujuan menjelaskan teks dan sekaligus menciptakan daya tarik. Kriteria ilustrasi yang berhasil dalam suatu media antara lain: komunikatif, informatif, dan mudah dipahami; menggugah perasaan dan hasrat untuk membaca; ide baru atau orisinal. Foto atau gambar harus punya kualitas memadai baik dari aspek seni maupun teknik pengerjaan (Supriyono, 2010:51). Gambar wayang pada bagian depan booklet sangat dominan dan pada halaman berikutnya terdapat gambar berbagai macam wayang, seperti wayang luar negeri dan dalam negeri. Dengan begitu, booklet ingin menginformasikan kepada masyarakat bahwa Museum Wayang memiliki berbagai macam koleksi wayang, mulai dari dalam negeri hingga luar negeri. Penggunaan gambar wayang 
semakin menekankan identitas booklet, hal itu sesuai dengan pendapat Parid Tirtosudiro bahwasanya penggunaan pola Wayang sebenarnya cukup unik untuk dijadikan element desain pada background sebuah desain dan hal tersebut dapat meningkatkan minat terhadap wayang itu sendiri.

4) Tata letak

Layout yang digunakan pada bagian dalam booklet jenis Jumble karena terlihat kesan ramai dari penyusunan gambar-gambar yang tidak beraturan. Jumble layout disebut juga dengan istilah circus layout, merupakan format tata letak yang memiliki kesan rumit serta ramai karena dalam format ini banyak menampilkan gambar-gambar dengan penataan yang tidak beraturan (Anggraini dan Nhatalia, 2014: 75).

5) Prinsip Desain pada Booklet

Kesederhanaan, terlihat terdapat pada bagian depan booklet dengan penggunaan satu jenis font. Keseimbangan (Balance), terdapat keseimbangan simetris pada booklet tersebut. Keseimbangan tidak dapat diukur, tetapi dapat dirasakan, yaitu suatu keadaan di mana semua bagian dalam sebuah karya tidak ada yang Saling membebani satu dengan yang lain (Yulius, 2016:44). Penekanan (Emphasis), terlihat pada penggunaan gambar wayang yang dominan, penuh satu lembar dan menarik perhatian. Hal senada disampaikan Stewart (2011:231) bahwa penekanan memberikan keunggulan khusus untuk bagian desain. Kesatuan (unity), terlihat adanya kesatuan antar elemen visual yang digunakan seperti penggunaan warna dasar dengan warna wayang itu sendiri. Kesatuan merupakan salah satu prinsip yang sangat penting, prinsip ini sesungguhnya saling berhubungan. Jika salah satu atau beberapa unsur rupa mempunyai hubungan (warna, raut, arah, dan lain-lain), maka kesatuan telah tercapai (Yulius, 2016:44).

\section{Post Card}

Kartu pos (post card) merupakan selembaran kertas karton tipis atau tebal berbentuk persegi panjang yang digunakan untuk menulis dan pengiriman tanpa amplop. Kartu pos menyajikan informasi yang lebih menarik, kombinasi antara fotografi dan tulisan deskriptif bertujuan agar pembaca tidak merasa bosan ketika hendak membaca informasi wisata tersebut (Apriliant, 2019: 31).

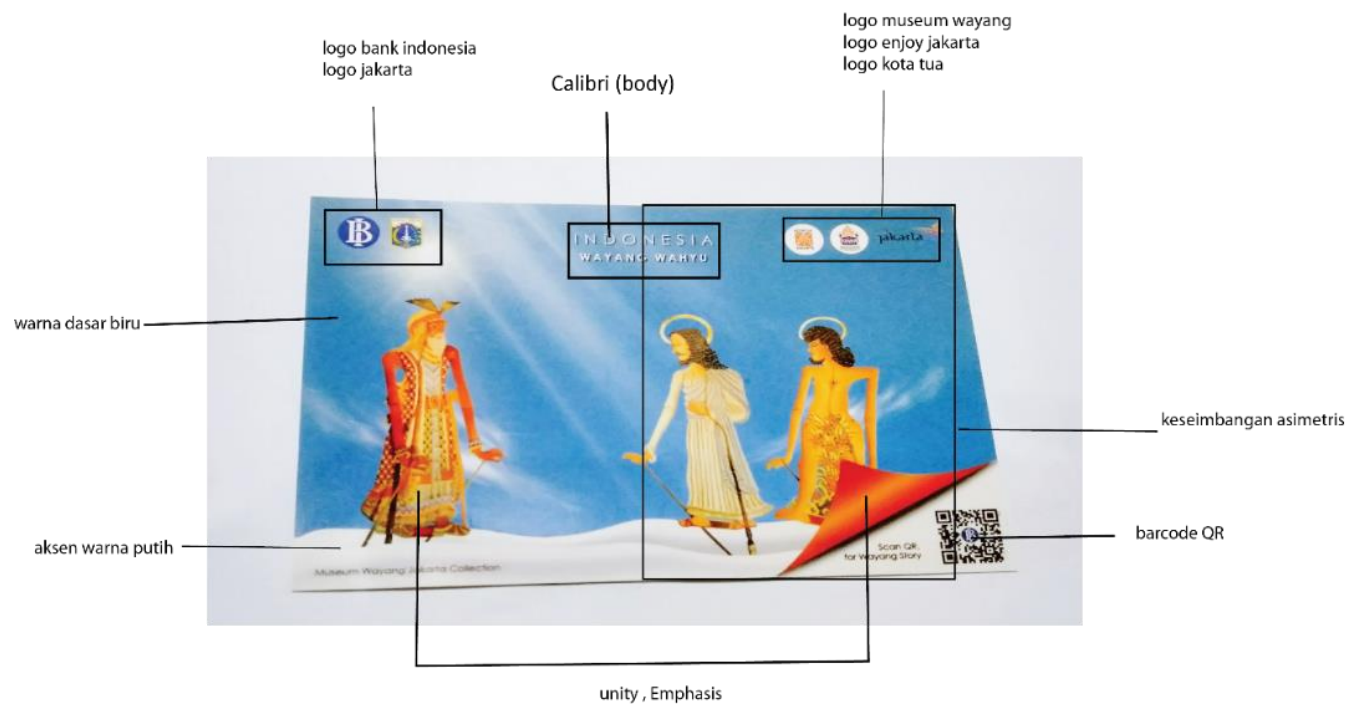

Gambar 3. Post Card

Sumber: Dokumen pribadi 
1) Warna

Secara objektif, menurut Krisnawati (2005), terciptanya warna karena adanya pigmen, dan menurut asosiatifnya warna biru diartikan langit, air, yang bermakna ketenangan, kemurnian, kesegaran. Biru menjadi warna dasar pada media promosi di atas, terdapat warna putih pada bagian bawah desain, dan aksen warna jingga pada bagian kanan bawah desain. Penggunaan warna biru sangat tidak membantu elemen-elemen wayang yang banyak menggunakan warna klasik seperti cokelat dan emas (Aryan Pramudito, 2020).

2) Tipografi

Jenis tipografi sans serif secara visual memiliki bentuk sederhana dan tidak formal sehingga sesuai untuk diimplementasikan untuk judul dan subjudul (Syahrul dkk., 2019:221). Terdapat satu jenis font sans serif yang digunakan pada post card, yaitu Calibri (body), hal itu semakin menekankan konsistensi karena digunakan pada di semua media promosi yang ada. Jenis font sans serif lebih menarik perhatian banyak orang dan memiliki tingkat keterbacaan yang jelas dan tidak monoton. Menurut (Wijaya, 1999:5) bahwa horisontalisasi yang terbutuhkan oleh kait, selain menimbulkan kesan monoton, juga menyulitkan mata pembaca ketika menyambung huruf demi huruf. Namun, beberapa jenis huruf tanpa kait telah diubah untuk mengatasi masalah tersebut. Pada masa kini huruf tanpa kait telah berhasil menarik perhatian banyak orang sehingga penggunaan font jenis san serif menjadikan kesan museum terlihat lebih stylish.

3) Ilustrasi

Ilustrasi dalam desain adalah untuk memperjelas teks dan sekaligus sebagai eye catcher (Supriyono 2010:169). Ilustrasi pada post card menggunakan gambar wayang wahyu, gambar lain seperti logo enjoy Jakarta, logo Museum Wayang, logo kota tua Jakarta, terdapat pada bagian kanan atas desain, bagian kiri atas terdapat logo DKI Jakarta dan bank Indonesia $Q r$ code berada di sebelah kanan bawah.

Peletakan logo pada bagian atas desain sangat menggagu visual, logo mitra biasanya berada di belakang atau bagian bawah desain agar tidak mengganggu.

4) Tata letak

Layout yang digunakan pada post card jenis layout axial terlihat dari kuatnya tampilan visual Wayang Wahyu yang di tampilkan. Layout axial sangat mirip dengan band layout, hanya saja memiliki lebih dari satu elemen yang muncul dalam tumpukan vertikal (Permana, 2014:17).

5) Prinsip desain

Kesederhanaan yang terdapat pada desain post card, terlihat dengan penyampaian informasi yang hanya satu jenis wayang, yaitu wayang wahyu dan tidak banyak menggunakan unsur-unsur aksesoris. Kesederhanaan berarti tidak berlebihan, berarti apa yang disampaikan adalah apa yang paling penting atau prinsipil. Sederhana berarti juga tepat, tidak lebih dan tidak kurang. (Pujiriyanto, 2005:29).

Keseimbangan (Balance) pada desain post card yaitu keseimbangan asimetris, hal itu terlihat pada penyampaian antarelement. Keseimbangan dapat dibagi menjadi keseimbangan simetris yang bersifat kokoh dan formal serta keseimbangan asimetris yang bersifat dinamis (Rustan, 2017: 80-82).

Kesatuan (Unity) tergambar pada penggunaan warna yang sama pada beberapa elemen, Unity merupakan kesan kesatuan dalam desain. Unity tidak hanya kesatuan antarelemen yang terlihat secara fisik, tetapi juga kesatuan antara fisik dan non-fisik, yaitu pesan yang dibawa dalam konsep desain (Rustan, 2017: 84)

Penekanan (Emphasis), terdapat pada penggunaa warna dasar biru yang membuat wayang wahyu menjadi lebih mencolok. Dengan begitu, kemencolokan tersebut bertujuan agar perhatian orang langsung tertuju pada bagian yang mencolok. Hal itu sesuai dengan pendapat Rustan (2017: 78) bahwa emphasis adalah penekanan desain. Emphasis digunakan untuk memberi penekanan agar sebuah elemen menjadi pusat perhatian. 


\section{SIMPULAN}

Pada media promosi booklet, brosur, post card, Museum Wayang Jakarta menggunakan beberapa elemen visual dan menerapkan prinsip desain. Identifikasi visual pada tersebut memperlihatkan kesederhanaan dan kemudahan visual dari sisi teknis visualnya maupun penggunaannya.

Warna yang digunakan ketiga media promosi, biru, putih, hijau, dan warna emas, dari ketiga media promosi menggunakan warna yang tidak konsisten, jadi tidak ada benang merah visual yang menghubungkan antara materi satu dengan yang lainnya

Tipografi yang digunakan oleh ketiga media promosi yaitu calibri (body) semua. Jenis font tersebut sederhana dan digunakan dalam media agar dapat terbaca cepat dan pesan atau informasi yang disampaikan dapat langsung dipahami, dan terdapat konsistensi penggunaan tipografi pada ketiga media promosi.

Ilustrasi yang digunakan ketiga media promosi sudah cukup memberikan informasi bahwa Museum Wayang memiliki berbagai macam jenis wayang, seperti adanya ilustrasi gambar bermacam-macam wayang baik dalam maupun luar negeri, khususnya pada media promosi booklet.

Layout yang digunakan pada media brosur dan post card jenis layout axial, sedangkan layout pada media brosur menggunakan jenis jumble layout.

Ada pengabaian terhadap prinsip-prinsip desain yang seharusnya diterapkan untuk menciptakan nilai estetis pada media promosi yang digunakan. Dari kelima prinsip desain yang ada, media poster ini hanya menerapkan dua prinsip desain, yaitu prinsip kesatuan dan keseimbangan (balance). Pada media booklet hanya menerapkan empat prinsip desain, yaitu prinsip kesederhanaan, keseimbangan (balance), penekanan (emphasis), kesatuan (unity), dan media post card hanya menerapkan empat prinsip desain, yaitu prinsip kesederhanaan, keseimbangan (balance), kesatuan (unity), penekanan (emphasis).

\section{DAFTAR PUSTAKA}

Aditya, B. M. (2015). Peran event and experience pada museum Jakarta (Tesis), Universitas Indonesia, Depok.

Anggraini, L., dan Nathalia, K. (2014). Desain komunikasi visual: Dasar-dasar panduan untuk pemula. Bandung: Nuansa Cendekia.

Anindita, M., dan Riyanti, M. T. (2016). Tren flat design dalam desain komunikasi visual. Jurnal Dimensi DKV Seni Rupa dan Desain, 1(1), 1-14.)

Apriliant. (2019). Perancangan informasi wisata Gunung Papandayan melalui media kartu pos. Universitas Indonesia.

Cenadi, C. S. (1999). Elemen-elemen dalam desain komunikasi visual. Nirmana, 1(1).

Gustaning, Guni. (2014). Pengembangan media booklet menggambar macam-macam celana pada kompetensi dasar menggambar celana siswa SMK $N 1$ Jenar (Tugas Akhir). Universitas Negeri Yogyakarta.

Hartanto, D. D. (2001). Penggunaan ilustrasi sebagai daya tarik pada iklan media cetak. Nirmana, 3(1), 40-48.

Krisnawati. \& Christina. (2005). Terapi warna dalam kesehatan, Yogyakarta: Curiosita.

Kusrianto, A. (2007). Pengantar desain komunikasi visual. Jakarta: Andi. 
Matondang, dan Fahmi, K. (2000). Pendidikan dan pelatihan teknis managemen dan kepemimpinan perpustakaan. Universitas Negeri Padang.

Novianti, A. (2017). Pola dan jaringan komunikasi tentang pengangkatan anak secara adat pepadun di kabupaten lampung tengah, (Skripsi). Universitas Lampung.

Permana, A. A. (2014). Perancangan desain media promosi company profil CV. Adeco Cipta Mandiri Sidoarjo. STIKOM Surabaya.

Pujiriyanto. (2005). Desain grafis komputer. Yogyakarta, Andi.

Ramadhani, A. R., \& Hariastuti R.T. (2018). Pengembangan booklet untuk bibliokonseling siswa dalam menangani perilaku salah suai di SMP Negeri 2 Candi Sidoarjo. Jurnal Bimbingan Konseling Universitas Negeri Surabaya 8(2), 359.

Rustan, S. (2017). Layout dasar dan penerapannya. Jakarta: Gramedia Pustaka Utama.

Rustan, S. (2011). Huruffont tipografi. Jakarta: Gramedia pustaka Utama.

Sabetti, Rian. (2011). Perancangan booklet studio gambar sebagai promosi jurusan seni rupa. (Tugas Akhir). Universitas Negeri Semarang.

Stewart, M. (2011). Launcing the imagination a comprehensive guide to basic design. New York: McGraw-Hill.

Supriyono, R. (2010). Desain komunikasi visual. Yogyakarta: Penerbit Andi.

Swasty, W., dan Utama, J. (2017). Warna sebagai identitas merek pada website. ANDHARUPA: Jurnal Desain Komunikasi Visual dan Multimedia, 3(01), 1-16.

Syahrul, Y., Rini, A., dan Fatmariani. (2019). Pelatihan pengenalan tipografi dalam meningkatkan psikomotorik anak bagi siswa siswi SD Negeri 17 Palembang. Politeknik PalComTech Palembang.

Vinsensius, S. (2004). Panduan mengenal desain grafis: Escaeva.

Wijaya, P. Y. (1999). Tipografi dalam desain komunikasi visual. Nirmana, l(1).

Yulistianti, dan Ana. (2008). Bekerja sebagai desainer grafis. Jakarta: Esensi erlangga group.

Yulius, Y. (2016). Peranan desain komunikasi visual sebagai pendukung media promosi kesehatan. Jurnal Seni, Desain dan Budaya, 1(2), 44.

Zharandont, P. (2015). Pengaruh warna bagi suatu produk dan psikologis manusia. Universitas Telkom. Bandung.

Zulkifli, T. R. (2018). Nirmana dwimatra elemen, prinsip, dan aspek aplikasi teknis seni rupa dan desain. Medan: FBS Unimed Press. 